\title{
Virtual Reality in Engineering Education: The Future of Creative Learning
}

http://dx.doi.org/10.3991/ijet.v6i4.1766

\author{
A. G. Abulrub, A. Attridge and M. A. Williams \\ The University of Warwick, Coventry, UK
}

\begin{abstract}
Virtual reality has achieved an adequate level of development for it to be considered in innovative applications such as education, training, and research in higher education. Virtual reality offers both opportunities and challenges for the educational sector. One of the challenges of virtual reality technology is the costs associated which have been unaffordable for educational institutes. However, in recent years, computer hardware and software development has made it more feasible to incorporate virtual reality technology into future teaching strategies.
\end{abstract}

Despite the cost challenges, educational benefits of implementing virtual reality remain compelling. This paper explains virtual reality principle and describes the interactive educational environment developed at WMG, the University of Warwick. It also discusses the benefits of using state-ofthe-art 3D photorealistic interactive and immersive virtual environment for engineering undergraduates and postgraduate teaching, learning and training.

Index Terms-Education, Engineering, Interactive, Virtual Reality, 3D Visualisation.

\section{INTRODUCTION}

Today, technology is as influential factor in education as it has ever been. A new generation of engineering students is entering higher education with significant computing knowledge, and with higher expectations that academic institutes will introduce them to appropriate technologies for their successful transformation into industry. Academic institutions are challenged by these new technological requirements and must adopt appropriate strategies to meet the innovative educational demand.

The advancement in interactive and immersive technologies can have a noticeable impact on various styles of teaching and learning. Virtual reality is a technology that is attractive to student community. Research in virtual reality and education is novel and has potential for expansion in the coming years.

Virtual Reality is largely used in military training [1], automotive and aerospace design [2], medical training [3], and entertainment [4]. 3D digital technologies are often a topic of applied research [5] and are already being adopted for commercial applications especially in the automotive premium industries i.e. Jaguar Land Rover integrate virtual reality concepts in the New Product Introduction (NPI) process in the design stage allowing 3D digital (virtual) prototypes to be utilised to make decisions in the early stages of design. Virtual reality also provides a suitable environment for design reviews helping to reduce the development time and costs and to improve the quality and usability of new products [2].
With the increasing demand for innovative in higher education for engineering, and with the advancement in $3 \mathrm{D}$ visualisation technologies and computer hardware, a growing range of engineering teaching and training material can be utilised in virtual reality environments. Virtual reality technologies can be used as educational and training tool with the advantages of being safe, cost-effective and fully controllable. Also, virtual reality environments enhance significantly the learning experience as they provide the learner with realism and interactivity.

However, engineering education is predominantly descriptive and complex. The application of virtual reality to such teaching has great prospects for new style [6]. The recognised technique in engineering education is the use of laboratory demonstrations to enhance the student's practical knowledge. Laboratories are designed to improve the student ability to investigate and solve engineering problems with appropriate levels of independent thought and creativity; and also to demonstrate suitable levels of reporting technical information [7]. Industry relies on distinctive skills to innovate and compete. Thus, it is essential for educational institutes to prepare for emerging technology in both infrastructures [8] and policies [9].

In this paper, the authors demonstrate the use of a 3D interactive virtual reality visualisation system in preparing engineering graduates for practical experience of real industrial environments with case studies obtained from world-leading businesses. The presented work shows that virtual reality technology can considerably improve the productivity of teaching and training by allowing engineers to apply theoretical knowledge to real industrial problems. In addition, it develops creativity and innovation, communication, problem-solving, team-working and business skills.

\section{3D VisULISATION WALL}

\section{A. 3D Virtual Reality Principle}

The main types of 3D visualisation technologies are active and passive. The system at WMG in the University of Warwick is designed as a passive technology; a schematic diagram of the 3D virtual environment system, including key components, is shown in Fig.1.

In active mode a single projector exchanges the right and left-eye images in sequence at a high frequency rate. Active stereo model viewer requires a set of active liquid crystal glasses that pass or block light through in synchronization with the images on the display screen. In a passive system two projectors sends overlapping images to the screen. The images are polarized using special filters and viewer requires a set of polarizing glasses. 
The human eye split light into three spectral ranges that are related to the main colors blue, green and red. Similarly, unique interference filters (dichromatic filters) separate the color spectrum into six narrow bands - two in the red (R1 \& R2), two in the green (G1 \& G2), and two in the blue (B1 \& B2) region. The $\mathrm{R} 1, \mathrm{G} 1$ and $\mathrm{B} 1$ bands are used to reconstruct an image for one eye, and the rest for the other eye. The human eye does not recognise fine spectral differences. The projectors and the glasess use the same filters to reconstruct the image. This technique provides full-color 3D images with slight colour differences that are unnoticeable to the human eyes.

\section{B. The Virtual Reality System at WMG}

The visualisation technology used is an ultra-highresolution, rear-projection, solution at the Visualisation and Metrology Centre of Excellence at WMG. The centre has various leading-edge technologies from the latest $\mathrm{X}$ ray CT scanning system to controlled lighting for colour harmony evaluation. The facility focuses on a unique workflow from data capture through to digital modelling.

The 3D visualisation suite within the centre is designed as a photo-realistic visualisation environment using advanced JVC $4 \mathrm{~K}$ 10Megapixel projectors to deliver the UK's highest resolution $4 \mathrm{~K}$ virtual reality wall to date as shown in Fig.2. The projectors are custom-fitted with Infitec (dichromatic) filters to provide crystal sharp immersive $3 \mathrm{D}$ visualisation on a $5 \mathrm{~m}$-wide fabric rear projection screen.

When running in fully immersive 3D mode, the system has an integrated camera-based infrared real-time tracking system for natural head and hand interaction and navigation of the virtual datasets and environments. The visualisation PC cluster controlling the imagery via two NVidia Quadroplex GFX units is specifically configured to drive graphic channels of very high resolution imagery, as illustrated in the schematic diagram in Fig.1.

\section{Software Support for Virtual reality}

$3 \mathrm{D}$ visualisation software packages provide engineering professionals and designers with a chance to experience the real-world sense of the product before making major investment in producing a prototype or manufacturing the real product. They also provide engineers with the necessary tools to precisely imitate real-world materials, light-

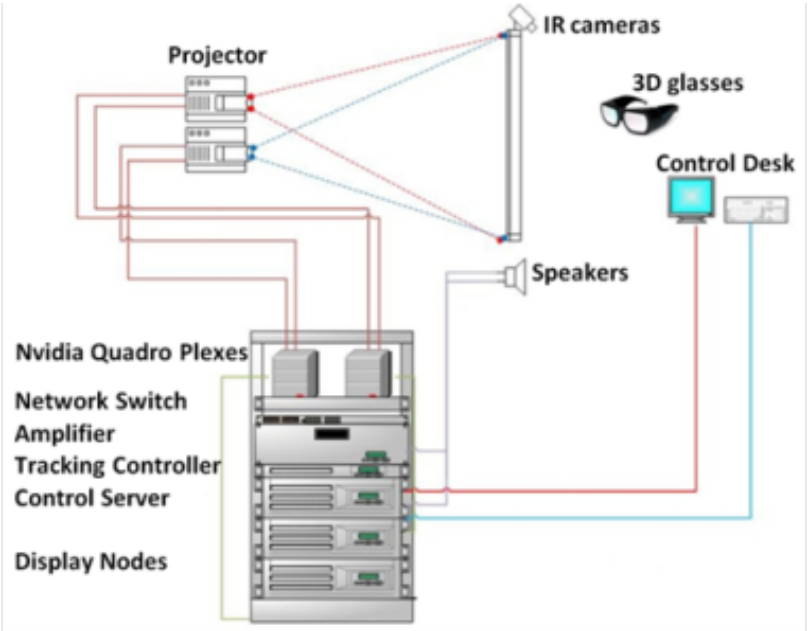

Figure 1. Schematic diagram of the University of Warwick's 3D visualisation system including projectors, cameras, speakers, control desk and network is shown ing and environments helping to increase confidence in making informed decision about the product design. They enable engineers to visualise design options, explore alternatives and evaluate designs in details.

The authors use Autodesk products [10] to achieve these requirements. Autodesk Showcase is being used in the current 3D virtual reality system with the support of the Aurora Showcase plug-in software, written by HoloVis, that enables Autodesk Showcase to operate in a passive stereo 3D immersive and tracked environments.

Autodesk Showcase is a real-time photorealistic design visualisation software package that enables users to prepare and present high-quality 3D designs as shown in Fig.3. Autodesk Showcase offers an easy and instinctive interface that drives a common-sense workflow with capabilities to have alternatives with different lighting and environments conditions. Also, it empowers virutal design process with multi-user network collaboration for development decisions to be made early in-design stages. The $3 \mathrm{D}$ digital prototype process is also supported with design specialist Autodesk Inventor that offers 3D design, simulation and tooling creation. The design can be shared with Autodesk Showcase for photorealist 3D experience in virtual environment.

Aurora, developed by HoloVis, is an enabler plug-in designed exclusively for Autodesk Showcase users to ensure maximum return from their existing software investment. It enhances the imagery, when used with an immersive and tracked display setup, by delivering the Autodesk Showcase solution in immersive 3D with support for head-tracking systems in real-time.

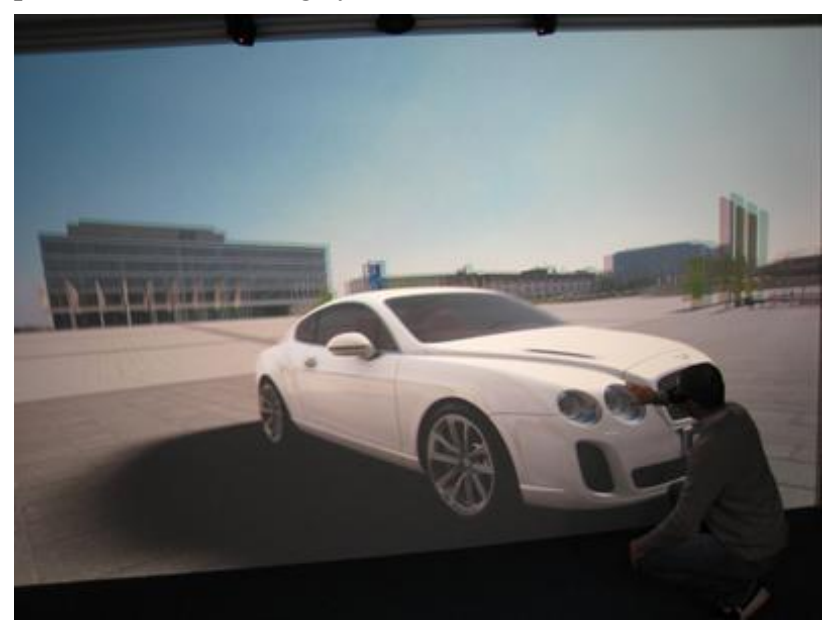

Figure 2. The 5m-wide fabric rear projection screen installed at WMG

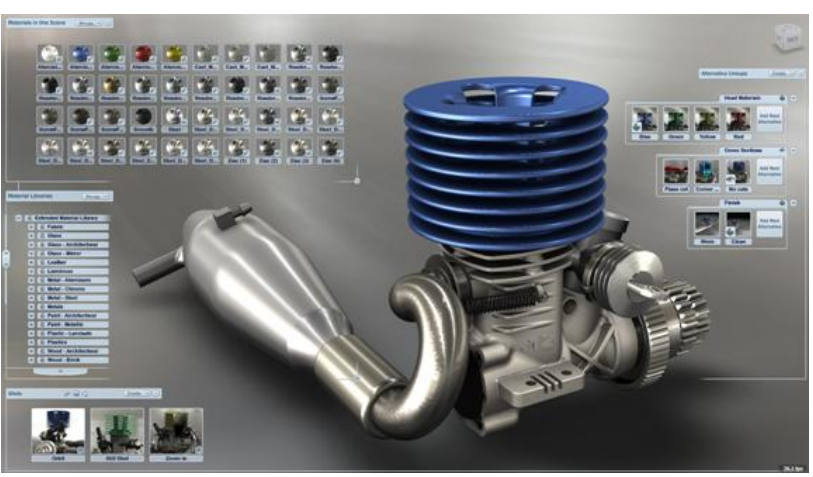

Figure 3. Autodesk Showcase 2011 showing an engine with various material option and alternatives. 


\section{Digital Prototy PING Process}

There is currently a trend for companies to express new products digitally, especially with the ease of use of data management systems. The digital models are integrated in the business to support their NPI process which may also use physical prototypes to verify innovative designs. However, with the advancement in 3D technologies and virtual environments, the intention is to reduce the physical prototypes to a feasible minimum by performing verification tasks early at the concept stage on a digital model. In the future, a better understanding of 3D digital prototyping in the manufacturing process will boosts the confidence in making decisions with anticipation to move away from physical models in the NPI process.

Sources of data for creating 3D digital prototypes in a virtual reality environment are diverse i.e. CAD, X-ray Computed Tomography (CT), laser scanner and others as illustrated in Fig.4. Regardless of the data source or type, it will need to be converted, optimised, and prepared for effective and efficient use in the virtual reality environment.

Importing CAD data into chosen visualisation software is not straightforward if the original data are not compatible. In workflow of the following case studies, the engineering student team uses Autodesk Showcase to define non-geometrical prerequisite i.e. material, light and shadow. The flowchart diagram in Fig.5 illustrates the procedure to ensure data is prepared with virtual reality requirement in mind. These requirements are orientation of normals, missing geometry or sub-assemblies, and optimisation (deletion of unwanted geometry). To achieve timely progress for virtual reality use, Autodesk Inventor was employed to prepare the engineering data and viewing it in $3 \mathrm{D}$ with basic non-geometrical data to be imported into the photorealistic Autodesk Showcase software.

\section{CASE Studies}

\section{A. Audit Review for Industrial Product}

In today's markets, products must exceed customer expectations. In automotive industry, this is a key aspect for a successful product that reflects high standards in visual, tactile and finishes [11]. Product evaluation in the NPI process is crucial to confirm these attributes for a competitive product. It is also necessary to evaluate product characteristics before the physical prototype stages as modify-

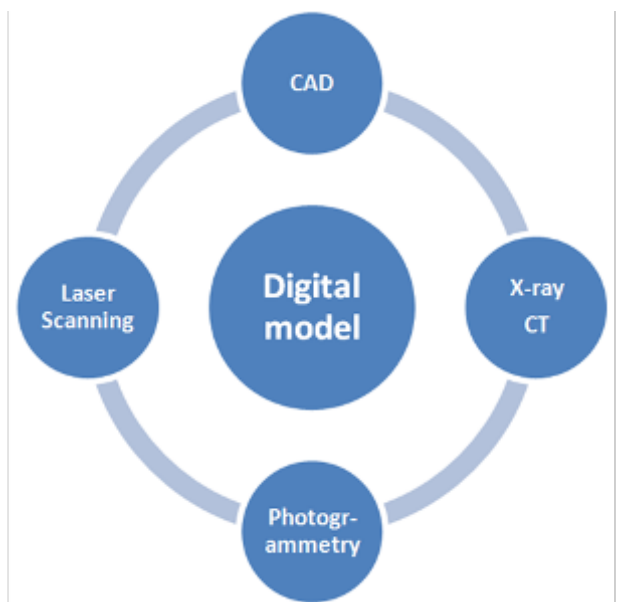

Figure 4. Autodesk Showcase 2011 showing an engine with various material option and alternatives. cations can be implemented quicker and at lowest cost compared to alterations made during production stages [12].

However, the existing operation of product evaluation has limited support of innovative technologies. 3D photorealistic visualisation in interactive virtual environment has the potential to improve the process in timely and cost effective manner.

Final Vehicle Product Audit (FVPA) process is a methodology aims to assess the product in the initial design stages to evaluate customer requirements and convert them from subjective measures into objective ones [13]. The work aims to apply an FVPA process in a virtual environment to evaluate a real-world product for one of WMG's industrial partners.

The audit process was carried out with interest in assessing gaps between interfacing components, paint and glass appearance and exterior decorations. However, the concerns are of visual type as tactile and sound categories cannot be identified using the current setup. The authors' future research and development will consider such challenges.

A sample of issues identified by the engineering student team is illustrated in Table 1 with its scoring using FVPA [13]; there were 88 additional concerns identified virtually.

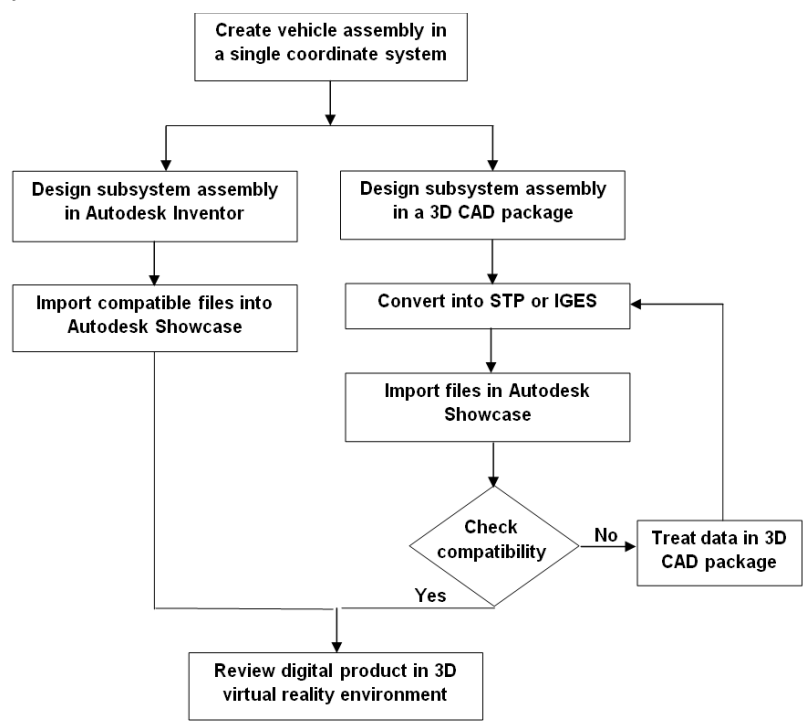

Figure 5. Procedure to prepare engineering CAD data for use in a 3D virtual environment

TABLE I.

SAMPLE OF VISUAL CONCERNS AND ITS RATING USING FVPA PROCESS

\begin{tabular}{|c|c|c|c|c|}
\hline S. No & Location & Description & Concern & Score \\
\hline 1 & $\begin{array}{c}\text { Handle } \\
\text { Bar } \\
\text { Assembly }\end{array}$ & $\begin{array}{c}\text { Colour harmony of } \\
\text { switches and the } \\
\text { surroundings parts }\end{array}$ & $\begin{array}{c}\text { Colour } \\
\text { harmony }\end{array}$ & C \\
\hline 2 & $\begin{array}{c}\text { Style } \\
\text { Parts }\end{array}$ & $\begin{array}{c}\text { Uneven gap be- } \\
\text { tween cover frame } \\
\text { and seat assembly }\end{array}$ & $\begin{array}{c}\text { Gaps and } \\
\text { Flush }\end{array}$ & E \\
\hline 3 & $\begin{array}{c}\text { Frame } \\
\text { Assembly }\end{array}$ & $\begin{array}{c}\text { Fastener visible } \\
\text { outside cover frame } \\
\text { assembly }\end{array}$ & $\begin{array}{c}\text { Visible } \\
\text { Fasteners }\end{array}$ & D \\
\hline 4 & $\begin{array}{c}\text { Seat } \\
\text { Assembly }\end{array}$ & $\begin{array}{c}\text { Seat hugging with } \\
\text { fuel tank }\end{array}$ & $\begin{array}{c}\text { Visual } \\
\text { Quality }\end{array}$ & D \\
\hline
\end{tabular}


Throughout the audit review, the vehicle assembly was divided into subsystems starting from the front end of the vehicle to the rear end. Figure 6 shows an example of an identified issue of "gaps and see through" condition, that can be resolved in the design stage and before committing to a physical prototype.

The project highlights the prospective role of virtual reality in the NPI process and its significant impact on quality, time and cost. Having an additional decision gate based on digital prototype early in the NPI process assists in developing a more robust process. The virtual environment assists the engineering team shown in Fig.7. to:

- Introduce the concept of digital prototype decision gate in the NPI process

- Identify additional issues using engineering data at concept stage

- Communicating and reporting the findings and the benefits of interactive $3 \mathrm{D}$ visualisation in the NPI process

- Recommendations on cost and time reduction in the NPI through the use of the technology

Autodesk Showcase solution software enables the user to create models from $3 \mathrm{D}$ CAD data to be imported into virtual environment as a digital prototype that is accurate, realistic and compelling. Figure 8 shows the level of details as a whole vehicle and selected parts demonstrating features of seat leather and the engine.

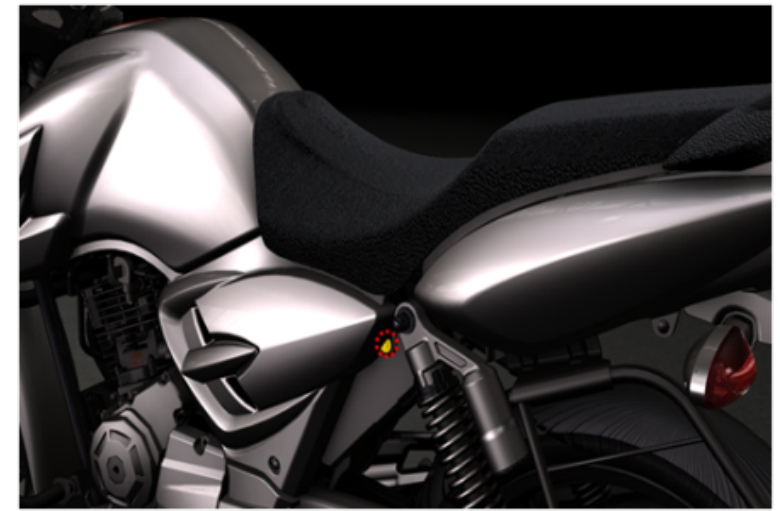

Figure 6. Identified concern using FVPA process in 3D visualisation virtual reality technology

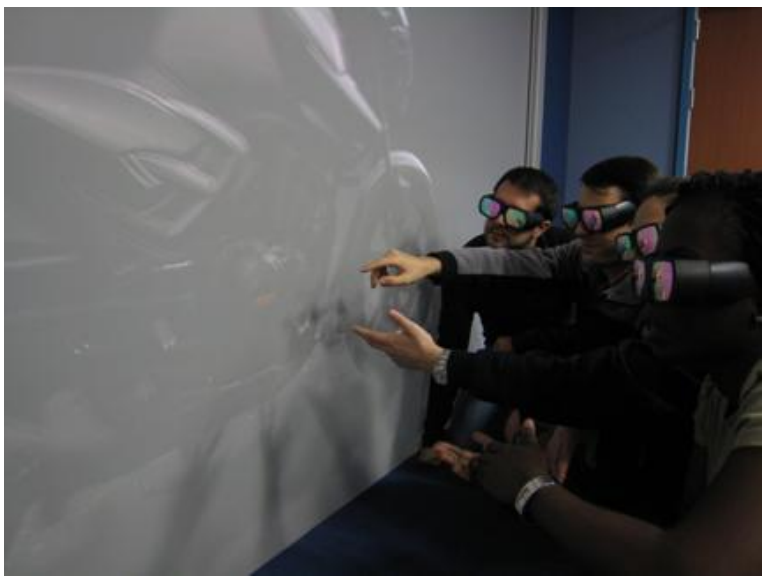

Figure 7. The student engineering team at Warwick executing the FVPA audit review process

\section{B. Warwick Formula Student Project}

Formula Student is well-known and one of the most important student motorsport competitions in Europe. It is managed by the Institution of Mechanical Engineers (IMechE) in affiliation with recognised sponsoring companies. It is intended to develop excellence in engineering graduate skills that meet industry expectations and need. Figure 9 shows the University of Warwick Formula team with their engineered car.

Warwick formula student project combines theoretical knowledge and learning with the development of practical engineering skills. It provides the future engineers with real-life experience in design and manufacture and the business aspects of automotive and engineering. The core challenge to the Formula Motorsport Student team is to design and fabricate a prototype car that best satisfies preset objectives and achieves learning aims. These are:

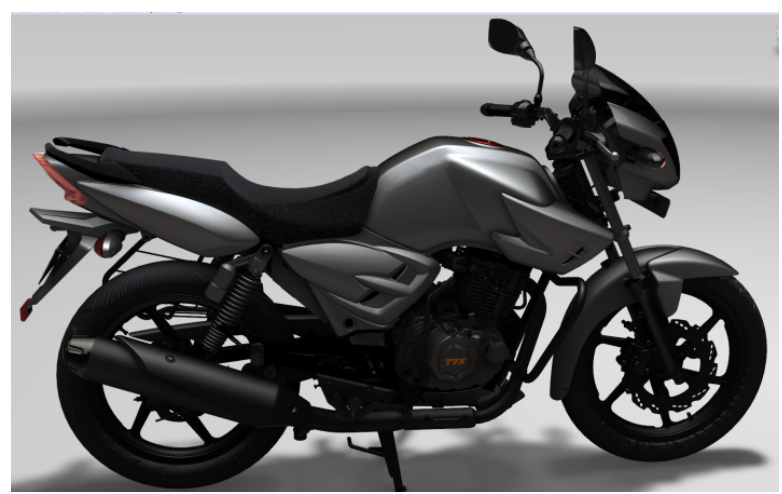

(a)
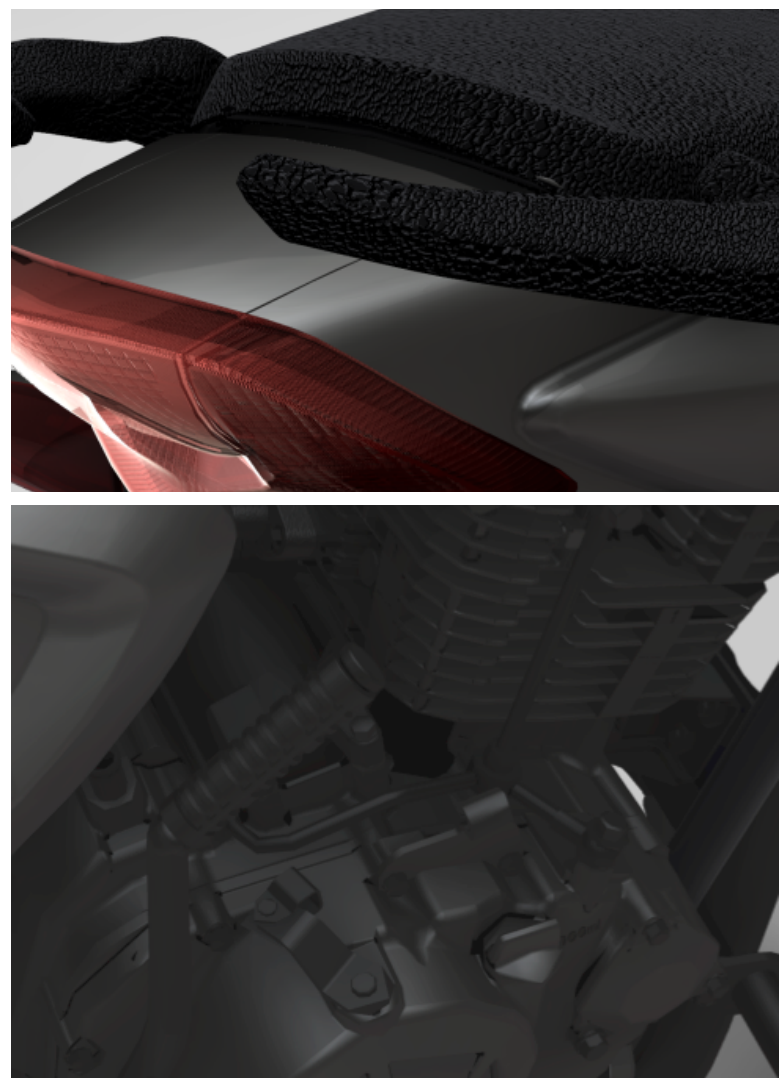

(b)

Figure 8. (a) Shows the digital prototype of whole product as viewed and examined on the 3D virtual environment (b) Shows the level of details (seat leather and engine parts) as observed in the environment 
- Design optimisation and engineering innovation

- Performance and functionality, designed car must pass tests on braking, fuel efficiency, speed and handling.

- Project planning and resource management

- Learning attitude; lessons from previous projects

- Successful product development and launch using NPI process

- Critical thinking and economical analysis

The team must also enhance their car's marketability to secure sponsors by improving the car appearance. This requirement encourages the team to develop business skills in order to be able to secure sponsors, build the car and compete. The University of Warwick team achieved the $7^{\text {th }}$ in the ranked order of UK universities and $22^{\text {nd }}$ worldwide competition.

Virtual reality is supporting the students to improve the NPI process and reduce cost associated with building a car on time for the competition, with the aim to achieve top three in the UK and top 15 internationally. The team uses 3D photorealistic virtual environments, as shown in Fig10, to:

- Increase marketability for sponsors using digital prototype. Alternative design and finish can be proposed in the sponsorship event.

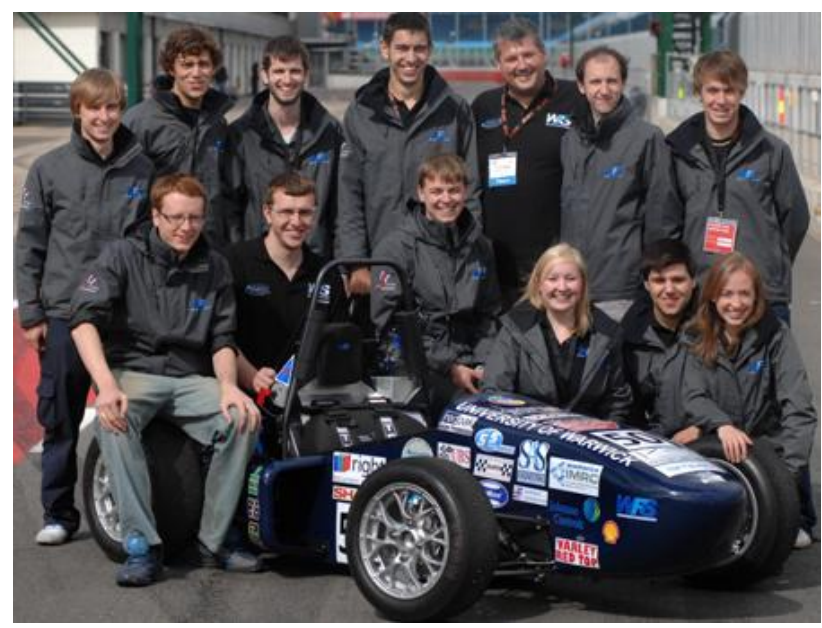

Figure 9. The University of Warwick Formula student team

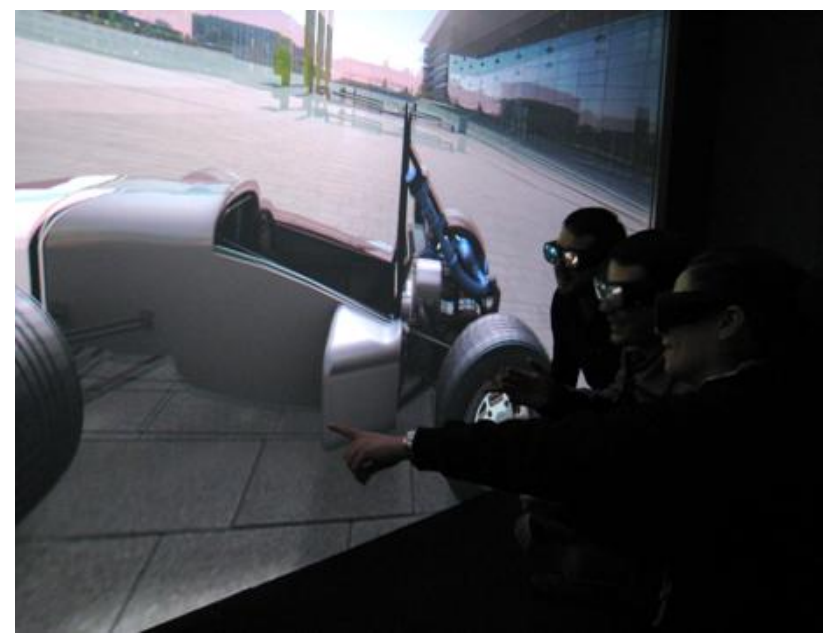

Figure 10. The Formula students using virtual reality to make design decisions early in the design
- Establish realistic plan for design and manufacture time.

- Ensure the vehicle complies with Formula Society of Automotive Engineers (FSAE) rules early in the design stage

- Create a strong collaborative culture within the team.

- Introduce the digital prototype concept into the NPI process

\section{Concept Design for First-Class Seat in A380}

Introducing new product with basic functionality is no longer accepted in the today's market. In general, the concept of product integration in our life is developed into a complex one. With the wide customer choice available, the customers can be more observant in their selection, and manufacturers now recognise that. For instance, in automotive industry, they must deliver a customer-focused experience rather than just a means of transport [14], to be commercially successful. 3D digital technology allows designers and business decision makers to deliver such a complex requirements.

3D digital prototyping models assist design teams to make better informed decisions by gaining valuable information about their concept design. The more understanding that is achieved at the early stage of new product development the better the chances of having a successful product in manufacturability and customer acceptance. If an innovative digital prototyping strategy is implemented, there is a better chance that the product will be introduced to the market on time, be accepted, and be profitable.

A partner company (Envisage Group in West midlands, the UK) has developed an advanced concept aeroplane seat for future business/first class passengers. The design was created digitally and a physical prototype was made but to clearly communicate the design to potential customers, 3D visualisation in a virtual environment was indispensable. The $3 \mathrm{D}$ virtual visualisation at WMG allowed the partner company to create exact 3D model of their innovative seat and demonstrate how it would appear within an actual plane. The technology allows potential customers to experience the innovative seat design on board the plane as demonstrated in Fig 11.

WMG offers its engineering graduate a rare opportunity to explore both the state of art technologies and real-life innovative projects. It provides the education community and businesses the necessary link as illustrated in the next section.

\section{Virtual Reality Role in Teaching AND Training ENGINEERING STUDENTS}

Virtual reality provides an innovative educational instrument for science [6] that enables students to assess the value of their solutions requiring them to apply relevant knowledge and understanding to a particular real-life complex problem. The interactive $3 \mathrm{D}$ environment also provides a suitable tool to break a complex problem into secondary ones and establish relationships between them to create a unique, realistic and practical solution.

Creating 3D models must be approached with clear intention and objectives which decide the level of details of the demonstrated model. These details i.e. material, light, shadow and surrounding, must be appropriate for the target objectives the engineer wants to achieve with the model as demonstrated n Fig.8 and Fig. 10. 

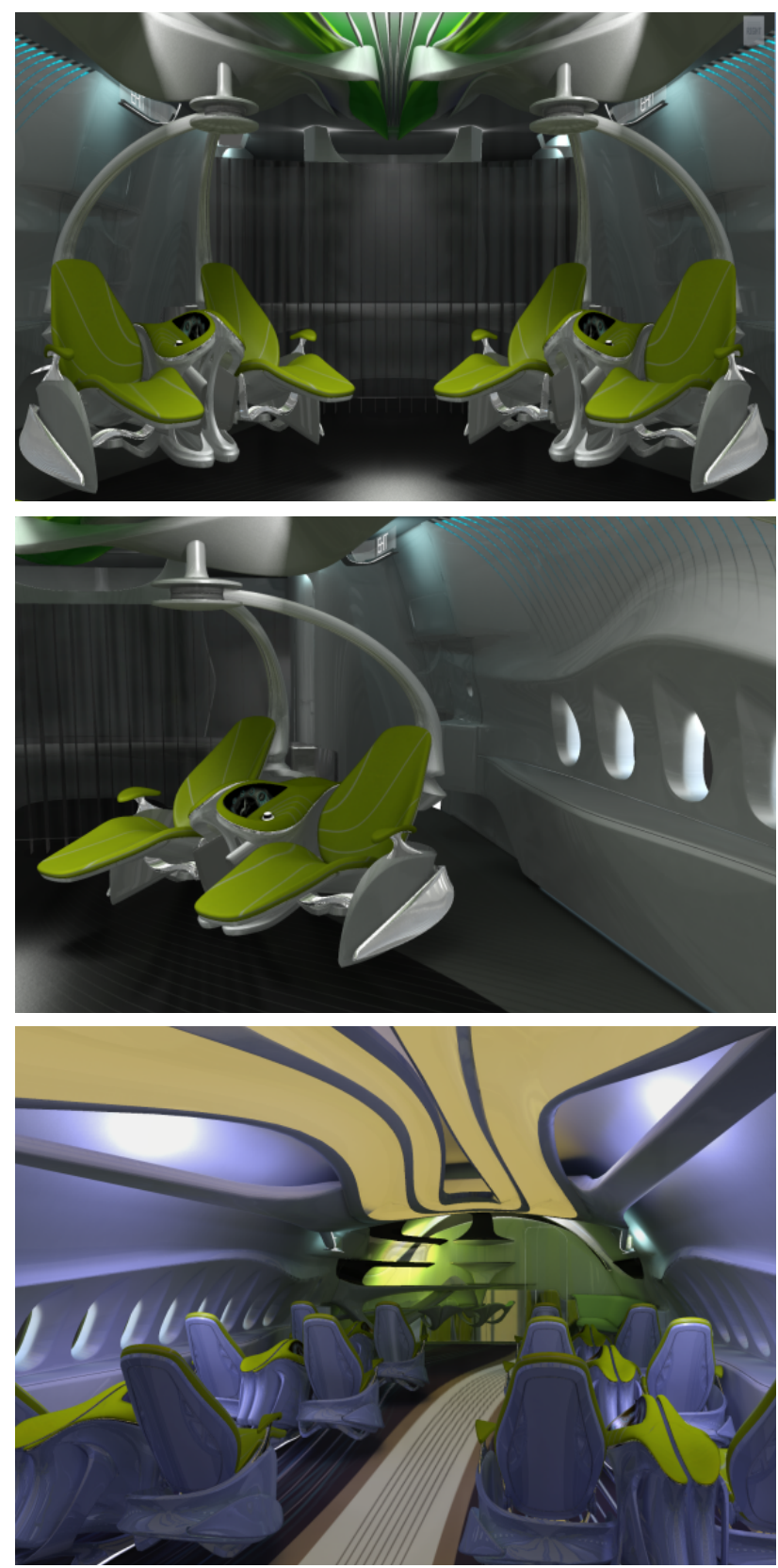

Figure 11. The future business/first class passengers seat in A380 aeroplane in a 3D virtual environment.

The chosen projects benefited from the virtual reality features such as $3 \mathrm{D}$ visualisation, photorealistic, interactive and immersive (sense of existence) to improve tangible learning outputs:

- Develop autonomous problem solving skills for reallife challenges.

- Share complex technical information with team members and professionals both verbally and in writing.

- Examine engineering problem in diverse modes; close inspection of an object or as a part of a whole system.

- Support creativity as it provides a chance for insight based on innovative technology.

- Encourage and develop effective communication skills among team members
- Apply knowledge and logic to conclude sound engineering opinion and decisions.

- Encourage to consider and propose different business solutions to achieve a specific task in practical terms for engineering problems.

The technology enables WMG to provide its engineering students with a virtual experiment and training system. It imitates various kinds of real-life engineering challenges that cannot be produced in traditional class room or laboratory due to cost or health and safety. The technology plays a vital role in supporting the education institutes as follow:

- Decrease assets cost in the long run as it can solve the problem of acquiring training rig/equipment, time and cost restrictions.

- Reduce the risk of hazardous material in training and teaching environments.

- Enhance the opportunity to explore inaccessible or restricted locations such as chemicals reactors.

- Reduce the impact on climate by cutting the wasteful material or eliminating harmful mistakes by learners

- Enable special-need engineering students to experience an environment when it is difficult to do that otherwise.

- Provide a platform for virtual lab to be utilised effectively in distance learning courses.

- Make student learning experience out of the ordinary which helps in branding the institute.

An effective engineering leader must have future awareness with strong technical knowledge and can think creatively and critically to define various feasible solutions. Interactive virtual environments encourage learner to develop leadership attributes such as effective communication, intellectual motivation, team working and individual confidence. There are several reasons for implementing virtual reality such as:

- It can enhance student motivation and attitude to gain knowledge

- Permit experiential learning through understanding real-life products

- Provide an opportunity for the students to explore technology through actual use

- Encourage active participation and amplify student interaction

Due to the poor economical climate, the global industry and SMEs are facing a difficult business environment. Thus, educating the $21^{\text {st }}$ century engineers requires accurate understanding of the current industry challenges. The industry requires graduate engineers to have advanced problem solving skills and apply theory to real world problems. Thus, engineering courses must be aligned with industry requirements and possibly managed in collaboration with industry [15].

WMG at the University of Warwick has strong links with industry and adopted the vision as a global leader in education to create an engineering generation that is educated based on strong collaboration between industry and academia to produce more inspiring engineers with the required skills. It also build on industrial engagement to benefit from its state of art technological advances in 
providing innovative solutions and develop an education system that trains engineers at all levels with sufficient skills to be employable in the challenging market environment.

3D virtual reality technology supports engineers to graduate with knowledge in using innovative technology to add value, reduce product time to market and make cost savings. It enables engineering students to understand how to define requirements earlier in the NPI process, thus reducing risk of lost profits and/or making products that do not meet customer expectations.

The industry needs engineering graduate, with distinctive knowledge and skills, to implement cost-effective innovative solutions that improve profit margins, differentiate their brands, reduce cost with guarantee on quality and product excellence. The authors believe integrating such an innovative technology in the educational and training of future engineers could be the way forward to fulfil the industry needs.

\section{CONCLUSION}

Interactive and immersive $3 \mathrm{D}$ visualisation virtual reality technology is an emerging technology that is promising for the engineering education and training. It represents a tool that can create a pipeline for cooperation with industry to prepare the next generation of graduate engineering with the skills required for business.

The authors demonstrate through real-life practical case studies how the innovative technology can be employed to produce creative learning and training engineering material and environments. The adopted technology in research and education meets the expectation of today's up-to-date student generation.

Although cost is recognised as a key challenge, leading educational institutes have already implemented the technology for research and education purposes. However, the more the technology advances, the more affordable it becomes. Thus, it is expected that additional institutes will implement the necessary hardware and software level for virtual reality to be strategically adopted in the future of engineering education.

\section{ACKNOWLEDGMENT}

This work is carried out as part of the Metrology and Visualisation Centre of Excellence Research centre part funded by Advantage West Midlands (AWM) and the European Regional Development Fund (ERDF). The authors would like to acknowledge the help of these two organizations in the funding of this research.

The authors also would like to acknowledge the cooperation of our partners; and express thanks for Autodesk and Holovis International for their valuable support on this research.

\section{REFERENCES}

[1] M. Zyda "From visual simulation to virtual reality to games", IEEE Computer Society 2005, Volume 38, Number 9, pp. 25-32. http://dx.doi.org/10.1109/MC.2005.297

[2] A. G. De Sa and G. Zachmann, "Virtual reality as a tool for verification of asembly and maintenance processes", Computer Graphics 1999, Volume 23, Number 3, pp. 389-403. http://dx.doi.org/10.1016/S0097-8493(99)00047-3

[3] A. G. Gallagher and C. U. Cates "Virtual reality for the operating room and cardiac catheterisation laboratory" The Lancet 2004,
Volume 364, Number 9444, pp. 1538-1540. http://dx.doi.org/ 10.1016/S0140-6736(04)17278-4

[4] C. Stapleton, C. Huges, M. Moshell, P. Micikevicius and M. Altman "Applying mixed reality to enterainment" IEEEComputers 2002, volume 35, Number 12, pp. 122-124. http://dx.doi.org/10.1109/MC.2002.1106186

[5] A. Attridge, M. A. Williams, and C. Tennant "The role of physical modelling in the design verification stage of the automotive NPI process in the premium sector", International Journal Of Automotive Technology And Management 2007,Volume 7, Number 1, pp. 32-54. http://dx.doi.org/10.1504/IJATM.2007.013382

[6] I. Kartiko, M. Kavakli and K. Cheng "Learning science in a virtual reality application: the impacts of animated-virtual actors' visual complexity", Computers and Education 2010, 55, pp. 881-891. http://dx.doi.org/10.1016/j.compedu.2010.03.019

[7] B. Balamuralithara and P. C. Woods "Virtual laboratories in engineering education: the simulation lab and remote lab" Computer Applications in Engineering Education, March 2009, Volume 17, Issue 1, pp. 108-118

[8] A. Y. Al-Zoubi, B. Kahhaleh, O. Hasan, and H. Kharouf "Future potential of ICT implemntation in univerity eEducation in Jordan" Conference ICL2007, Septmeber 26-28, pp.1-9, Villach, Austria.

[9] F. Lamb, C. Arlett, R. Dales, B. Ditchfield, B. Parkin and W. Wakeham "Engineering graduates for industry" Feb 2010, The Royal Academy of Engineering, pp. 1-64, London, UK.

[10] Autodesk Showcase 2011 Realease "http:/www.autodesk.co.uk/"

[11] T. Wellings, M. Williams and C. tennant "Tactility, craftmanship and the NPI process" Proceedings of the SAE 2005 World Congress and Exhibition, April 2005.

[12] A. Attridge, M. Williams and C. Tennant "Achieving craftsmanship targets across the UK automotive supply base, through the use of quality maturation tools and processes". Proceedings of the SAE 2005 World Congress and Exhibition, April 2005.

[13] G. A. Turley, M. A. Williams and C. Tennant "Final vehicle methodologies within automotive indsutry" International Journal of Productivity and Quality Management 2007, Volume 2, Issue 1, pp. 1-22. http://dx.doi.org/10.1504/IJPQM.2007.011465

[14] Williams, M.A., Attridge, A. and Pitts, M. (2011) 'User-centred design and evaluation of automotive seat adjustment controls', Int. J. Vehicle Design, Vol. 55, Nos. 2/3/4, pp.119-138.

[15] N. Spinks, N. Silburn and D. Birchall "Educating engineers for the $21^{\text {st }}$ century: the industrial review" The Royal Academy of Engineering 2006, UK

\section{AUTHORS}

A. G. Abulrub is a Research Fellow at WMG, the University of Warwick. He served as a postdoctoral fellow at Power Transmission and Motion Control Centre, the University of Bath from 2006-2009 where he currently holds an honorary position as a visiting fellow.

Dr. Abulrub received his BSc in Mechanical Engineering from Mu'tah University, Jordan in 2000. He was awarded his M.Sc. and Ph.D. degrees in mechanical engineering from the University of Bath, the UK in 2002 and 2007, respectively. He is a Chartered Engineer with the Institute of Mechanical Engineers and a member of Chartered Management Institute from which he was awarded a professional diploma in management and leadership.

Following his arrival at WMG, Dr. Abulrub worked as a research fellow in the Metrology and Visualisation Centre and currently, is responsible for the UK highest 3D visualisation suite which is part of $£ 5$ million project funded by AWM and ERDF. The project is in partnership with more than 20 industrial partners including Jaguar Land Rover, TATA, Autodesk, Arup, Nikon, Holovis International and other leading industries.

His research lies mainly in the innovation management within SMEs as an instrument to develop pioneering processes that add business value by reducing cost and time. 
He is an author of two book chapters by Springer, and is author, or co-author of more than 15 other publications.

A. Attridge is a Senior Research Fellow at WMG, University of Warwick. He was awarded an MEng (Hons) in 1999 and a $\mathrm{PhD}$ in 2003, both from the University of Birmingham. He is currently team leader of an EPSRCfunded research project developing and evaluating future automotive HMI solutions, Project Manager of a $£ 5 \mathrm{M}$ Regional Development Agency/European Regional Development Fund Centre of Excellence, and is involved in a Technology Strategy Board funded project. He is also involved in undergraduate and postgraduate teaching and project supervision in the fields.

M. A. Williams is a Professorial Fellow at WMG, The University of Warwick. He served a four-year apprentice- ship and gained a BEng (Hons) in Mechanical Engineering from Nottingham University in 1993 and a $\mathrm{PhD}$ from the University of Manchester in 1998. He also spent five years in industry with Jaguar Land Rover, and was made a Fellow of the IMechE in 2007. He is currently leader of the Product Evaluation Technologies research group at WMG, which carries out research into the development of advanced metrology systems and human-machine interface (HMI) technology, with funding from EPSRC, Technology Strategy Board and the regional development agencies.

This article is a modified version of a paper presented at the International Conference IEEE EDUCON2011, held in April 2011, at Princess Sumaya University for Technology in Amman, Jordan. Received 17 August 2011. Published as resubmitted by the authors on 22 November 2011. 